\title{
Use of a Numerical Tool to Assess the Impact of the Means of Measurement on Fire
}

\author{
SYLVAIN DESANGHERE ${ }^{1}$, DANIEL JOYEUX ${ }^{1}$, and ALEXIS COPPALLE ${ }^{2}$ \\ ${ }^{1}$ Certification and Fire division, CTICM \\ Domaine de Saint-Paul \\ F-78471 Saint Rémy Les Chevreuse Cedex - France \\ ${ }^{2}$ UMR 6614 CORIA \\ BP- 08 Av de l'Université \\ F-76801 Saint Etienne du Rouvray - France
}

\begin{abstract}
Experimental results are generally used as reference for validation of numerical tools. Afterwards, calculation tools can be used to extend the study by getting numerical results concerning slightly different cases. The present application is somewhat different. It is aimed at evaluating the relevance of experimental results by using numerical tools to analyze the test results and to know up to what extent the experimental device can disturb the fire test.

In the present paper, an experimental test simulating a hotel bedroom fire was performed in a compartment using pieces of furniture. During post-flashover period of the fire, external flames emerging from the opening were observed. The combustion gases flowing out of the room were collected by a calorimeter hood placed above to determine the heat release rate by oxygen consumption. In order to assess the impact of the calorimeter hood on the fire within as well as outside the room, two numerical simulations are compared. The first one is aimed at reproducing the test as well as possible in order to adjust some numerical parameters. The second one is used to simulate the same case without the hood to evaluate how it affects the flow and consequently the fuel/air exchange within the compartment.
\end{abstract}

KEYWORDS: compartment fire, numerical simulation, CFD, oxygen consumption calorimetry, heat release rate, experimental results analysis

\section{INTRODUCTION}

Oxygen consumption calorimetry provides a means of estimating the heat release rate of a fire by measuring changes in oxygen concentration within combustion gases $[1,2]$. This technique is now widely used all over the world both in bench-scale and full-scale fire test application. To ensure correct estimation of heat release, all the combustion gases have to be collected by a hood surmounted by an exhaust duct in which their composition is analyzed.

This device can have an effect on the fire when placed too close to the experiment. Indeed, the flows above the fire test are affected by the presence of the hood, the pressure field can be modified, and radiation from the hood itself may play a part in the physical processes of the fire [3,4]. On the other hand, the hood has to be located not too far from the fire in order to avoid spill over and significant dilution of combustion products [5]. This problem, which often arises in the case of full-scale fire test, raises the question to quantify the influence of the measurement on the fire. The reliability of the experimental results depends naturally on this influence. 
A simple way to have an estimation of that effect on the fire test is firstly to model the case using a numerical tool and secondly to re-simulate it without the device. This procedure requires thus two numerical simulations. The first one is aimed at checking the relevance and the accuracy of the model which is the basis of the calculations. The agreement between experimental and numerical results ensures that the numerical tool is correctly used to simulate that fire test. A second numerical simulation is then performed, in which the only difference is the removal of the device. Finally, the comparison between the two numerical simulations can help to assess the influence of the experimental device.

In this paper, this methodology is applied to the case of a hotel bedroom fire test performed in a compartment built under a calorimeter hood of close size.

\section{EXPERIMENTAL TEST}

\section{Description}

Within the framework of a study which was partially financed by the French ministry of Interior, a feasibility study of Fire Safety Engineering concerning a hotel in Paris has been realized by CTICM and CSTB [6,7], and several hotel fire tests were performed by CTICM [8]. Real pieces of furniture have been laid out in a compartment in a realistic way (see Fig. 1) and the fire was initiated with the ignition of a single item. Its development has been natural and the typical behavior of compartment fire has been observed, with flashover followed by a fully-developed fire period.

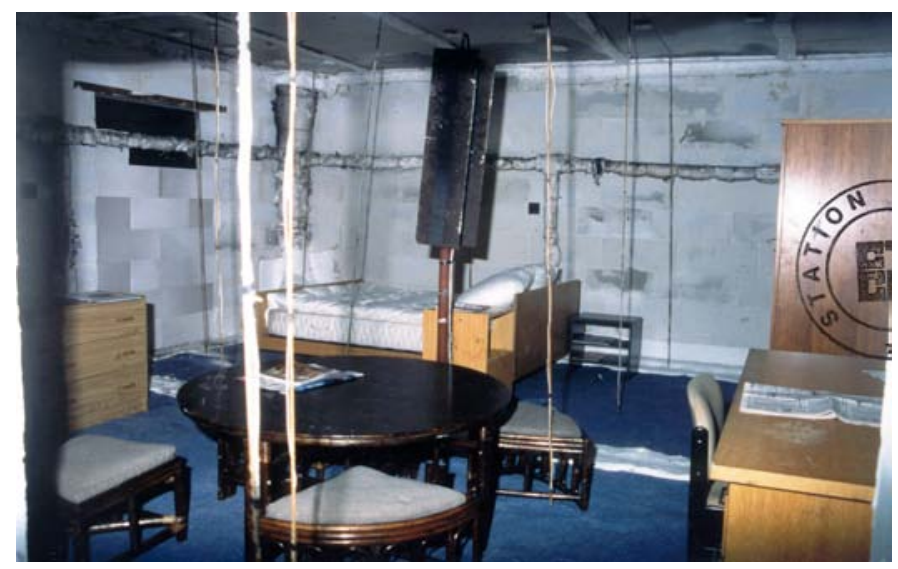

Fig. 1. Fire load distribution.

The compartment used for the fire test is $5.70 \mathrm{~m}$ long, $5.50 \mathrm{~m}$ wide and $2.80 \mathrm{~m}$ high (Fig. 2). Its opening is $1.40 \mathrm{~m}$ wide and $1.90 \mathrm{~m}$ high. Its walls are made of cellular concrete. 


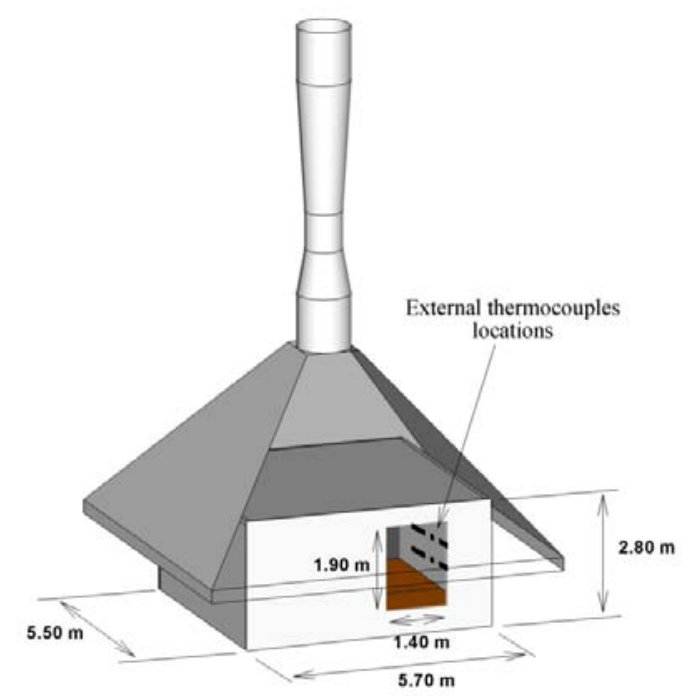

Fig. 2. Overview of the compartment and the hood above.

\section{Heat Release Rate}

The experimental heat release rate (HRR) is the main input value for the numerical simulations, as the fuel flow is imposed in the present calculations. The experimental heat release rate measured by oxygen consumption is represented by circles in Fig. 3. The occurrence of a fully developed fire stage leads to a plateau shape for the HRR curve. The simulated period, also shown in Fig. 3, starts when the heat release reaches significant values and lasts for 1200 seconds. The beginning of the fire (shown in Fig. 4) is not particularly studied in this paper. The bold line in Fig. 3 is the simplified HRR curve used as input for the numerical tool. Within this curve, the experimental peak values of heat release rate have been withdrawn. Only a basic curve is used for simulation to make the observations easier.

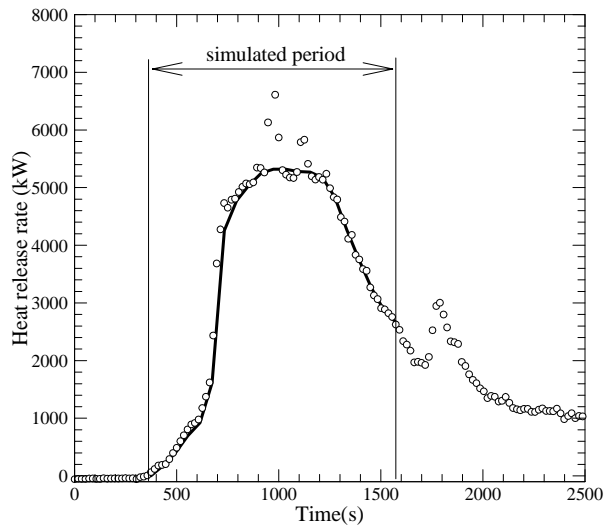

Fig. 3. Heat release rate during experimental test (circles) and input heat release rate for numerical simulations (bold line). 


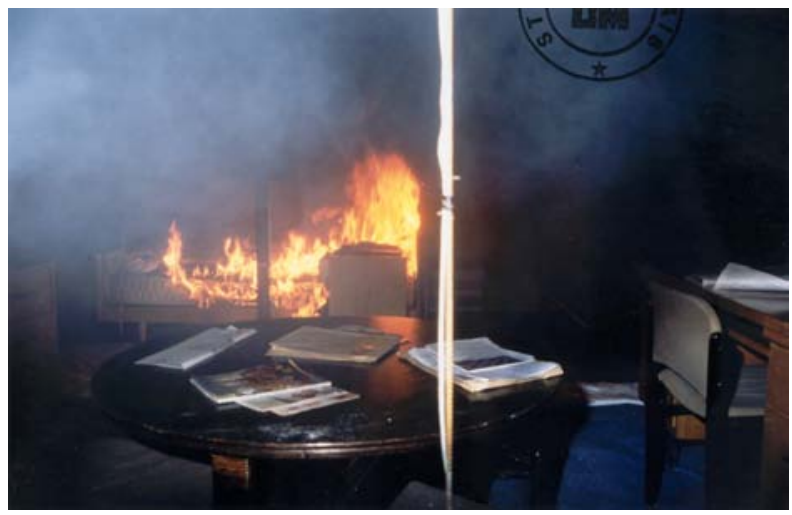

Fig. 4. Beginning of the fire by ignition of the mattress.

\section{NUMERICAL SIMULATIONS}

\section{CFD Model Description}

The numerical tool used in this work is based on the version 4 of the Fire Dynamics Simulator (FDS) developed by NIST Building and Fire Research Laboratory [9]. FDS solves an approximation of the Navier-Stokes equations appropriate for low-speed, thermally-driven flows. The numerical algorithm employed is an explicit predictor/corrector scheme, second order accurate both in space and time, using a direct Poisson solver. Turbulence is treated by means of Large Eddy Simulation, via the classical Smagorinsky subgrid scale model. A mixture fraction combustion model assuming unique infinitely fast global chemical reaction is used to estimate the heat release distribution in the computational domain. In order to track species, the FDS suppression algorithm [9] is not used in this work, so that fuel and air always burn when mixed, without any condition. The radiation transport is treated by means of a finite volume solver in which grey gas absorption coefficient for soot and gas species is linked to the mixture fraction. Heat transfers to walls are estimated by 1-D solver on each wall cell, accounting for wall thermal properties. Except for the heat of combustion, all parameters values employed for the simulation are the default ones used by FDS.

\section{Global Chemical Reaction Used}

The global chemical reaction in the simulations corresponds to a wood-like fuel:

$$
\mathrm{CH}_{2} \mathrm{O}_{0.8}+0.93\left(\mathrm{O}_{2}+3.76 \mathrm{~N}_{2}\right) \rightarrow 0.82 \mathrm{CO}_{2}+\mathrm{H}_{2} \mathrm{O}+0.03 \mathrm{CO}+0.16 \text { soot }+3.5 \mathrm{~N}_{2}
$$

An important parameter in the simulation is the heat release per kilogram of oxygen consumed. The experimental measurements have led to a heat of combustion of $16.6 \mathrm{MJ} / \mathrm{kg}$ of fuel burnt. This value was used in the simulations and the corresponding value of the heat of combustion of oxygen was $14.93 \mathrm{MJ} / \mathrm{kg}$. This is a little bit higher than the reference value used by many authors, which is $13.1 \mathrm{MJ} / \mathrm{kg}$. The soot production coefficient was arbitrary chosen considering the type of fuel involved. 


\section{Numerical Grids}

The first numerical simulation (simulation 1) domain is shown in Fig. 5. A first mesh of approximately 260000 cells is used to simulate the compartment and the hood above, while a second one comprising 9000 cells is used to model the exhaust duct. The grid is uniform and the cells dimensions are $10 \mathrm{~cm}$ by $10 \mathrm{~cm}$ by $12.5 \mathrm{~cm}$. This represents a compromise between flow resolution and computational time. No grid size effect analysis has been performed on this particular case. The focus of this work is to use the same grid size in both simulations for a grid-size independent comparison.

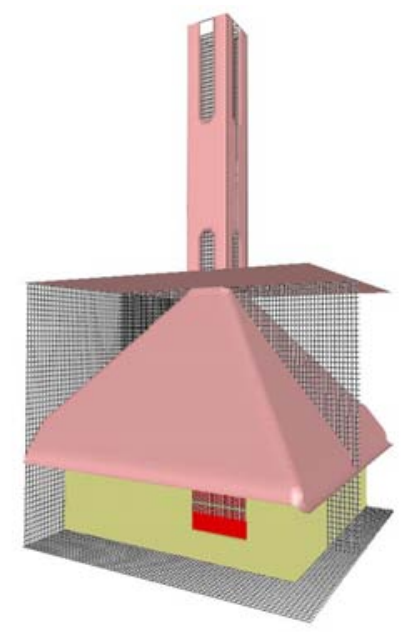

Fig. 5. Overview of the numerical grid for simulation 1.

The second numerical simulation (simulation 2) uses the same mesh as the first one but without any hood. The cells dimensions are the same between the two simulations to avoid as much as possible variations due to different numerical grid size. Each simulation took roughly 40 hours on a Pentium 4 HT $(3.2 \mathrm{GHz})$ processor.

\section{DISCUSSION}

\section{Agreement Between Simulation 1 and Experimental Results}

The quite good agreement between CFD simulation and experimental results concerning internal average temperature in the compartment is shown in Fig. 6. In this figure is reported the mean temperature averaged over the room. These numerical and experimental values correspond to an average over 12 thermocouples distributed uniformly within the room. The numerical simulation uses thermocouples placed at the same locations than experimental ones.

The shape of the calculated temperature curve is similar to the shape of the heat release rate curve given as an input for the simulation. This later is a simplified representation of the real curve. That can explain why the shapes of the two curves in Fig. 6 are slightly different. 


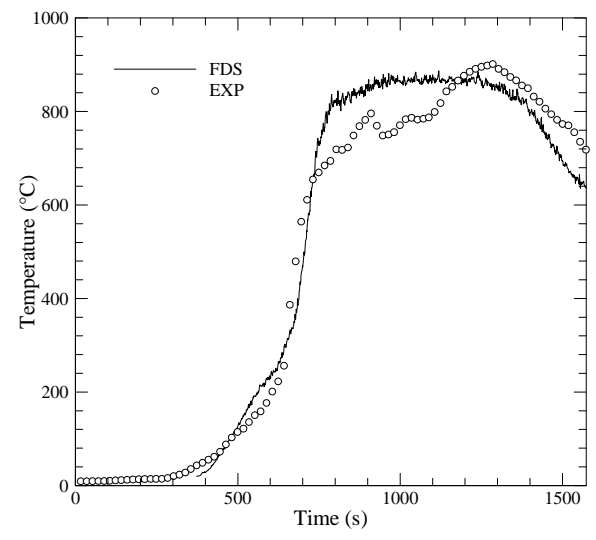

Fig. 6. Average temperature within the compartment.

Figure 7 shows also a relatively good agreement between CFD simulation and experimental results concerning external temperatures. These values correspond to an average over two thermocouples placed in two horizontal lines located at the top and at two third of the height of the opening and in the middle of its width (see dash dotted lines in Fig. 2). The first thermocouple is close to the opening whereas the second one is $60 \mathrm{~cm}$ in front of it. Once again, the curves for the calculated temperatures present similar shape with the input heat release curve.

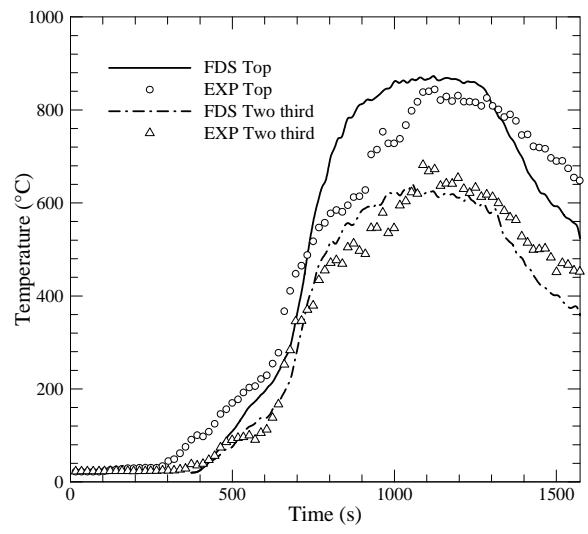

Fig. 7. External temperatures in two planes.

See Fig. 2 for the planes locations.

Emerging gases temperatures are higher during the test at the top of the window than their calculated values. This can be explained by the fact that only few items are burning in the test whereas the average pyrolysis rate is distributed uniformly on all the surface of the floor in the simulation. This assumption of a uniformly distributed pyrolysis rate, with a maximum value close to $200 \mathrm{~kW} / \mathrm{m}^{2}$, is used here for the sake of simplicity. However, relatively high local heat release rates are not reproduced by the simulation, whereas this is observed in the photo given in Fig. 4, where the fire is localized to the mattress. Nevertheless, the issue of source modeling is not the focus of this work. 
Figure 8 shows the exhaust gases composition in the duct predicted by CFD simulation. It is interesting to note that FDS well reproduces mixing processes within the venturi duct because time evolution of $\mathrm{CO}_{2}$ and $\mathrm{O}_{2}$ are in good agreement with measurements, in spite of the simplicity of the models used in FDS.

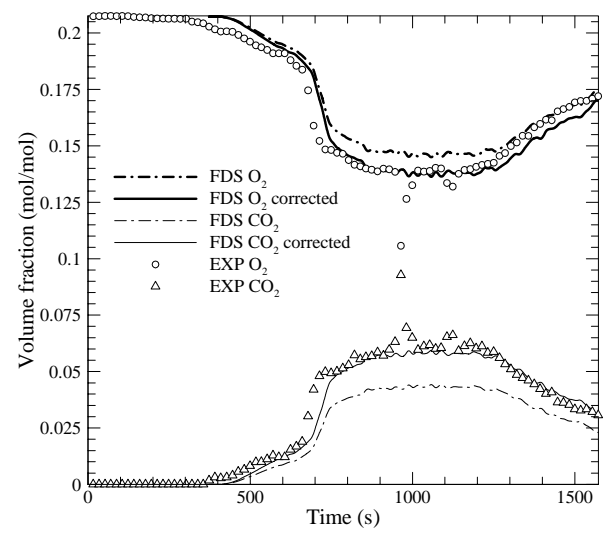

Fig. 8. Combustion gases composition in the exhaust duct.

However, compared to measurements, values given by FDS are underestimated concerning oxygen consumption and $\mathrm{CO} 2$ yield during fully developed period. This comes from the fact that they are predicted with the assumptions on fuel characteristics given above. Table 1 gives experimental and calculated values of $\mathrm{CO}_{2}$ yield and $\mathrm{O}_{2}$ consumption. The measured value was determined from the cumulative $\mathrm{CO}_{2}$ mass and the cumulative $\mathrm{O}_{2}$ consumed mass in the hood and the total lost mass measured by a weighing platform. The ratio between experimental and assumed rates (consumption and production) is also given in the table. It has been applied for corrections of predicted values of $\mathrm{CO}_{2}$ and $\mathrm{O}_{2}$ concentrations. These corrected values are shown in Fig. 8. In fact, a fuel written $\mathrm{C}_{1.6} \mathrm{H}_{1.4} \mathrm{O}_{0.8}$ presents characteristics better corresponding to experimental data. But it was preferred to use a more common fuel (with wood characteristics) used by the fire engineering community.

Same approach is used for CO concentration. The comparison is not shown here, but the agreement is acceptable. An experimental CO yield of $0.076 \mathrm{~kg} / \mathrm{kg}$ of fuel was recorded, whereas a $\mathrm{CO}$ yield of about $0.02 \mathrm{~kg} / \mathrm{kg}$ of fuel is used in the simulation. The experimental CO is relatively high compared to usual values measured in fire conditions.

Table 1. Experimental and calculated values of $\mathrm{CO}_{2}$ yield and $\mathrm{O}_{2}$ consumption.

\begin{tabular}{|l|l|l|l|}
\hline Conditions & Test & Simulation & Ratio \\
\hline $\mathrm{CO}_{2}$ yield $(\mathrm{kg} / \mathrm{kg})$ & 1.82 & 1.34 & 1.36 \\
\hline $\mathrm{O}_{2}$ consumption $(\mathrm{kg} / \mathrm{kg})$ & 1.26 & 1.14 & 1.10 \\
\hline $\mathrm{CO}$ yield $(\mathrm{kg} / \mathrm{kg})$ & 0.076 & 0.02 & 3.8 \\
\hline
\end{tabular}

\section{Analysis of the Fire Test}

Figure 9 shows a comparison between input heat release rate and its calculated value from the gas composition in the venturi, both for simulation 1 . The difference 
corresponds to the part of combustion gases which was not collected by the calorimeter hood. This variation is negligible $(<1 \%)$, confirming the visual observations made during the test. An additional time shift corresponding to a delay between fuel emission and oxygen depletion measurement in the duct is clearly visible when comparing the two curves. That point finally ensures the reliability of the experimental measurements.

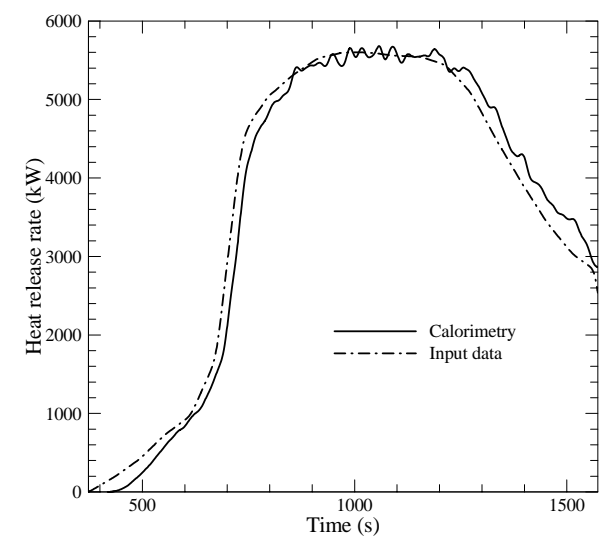

Fig. 9. Heat release rates: Comparison between input data and values deduced from gas composition in the exhaust duct.

\section{Influence of the Calorimeter Hood}

The two numerical simulations are now compared. The effect of hood on external temperature field is shown in Fig. 10. The contour plots of an average temperature field (over $100 \mathrm{~s}$ during fully developed fire) are presented for each case to show the deflection of the flames. The slice considered here is located at the middle of the opening. The contour lines correspond to isothermal lines for every $100^{\circ} \mathrm{C}$.
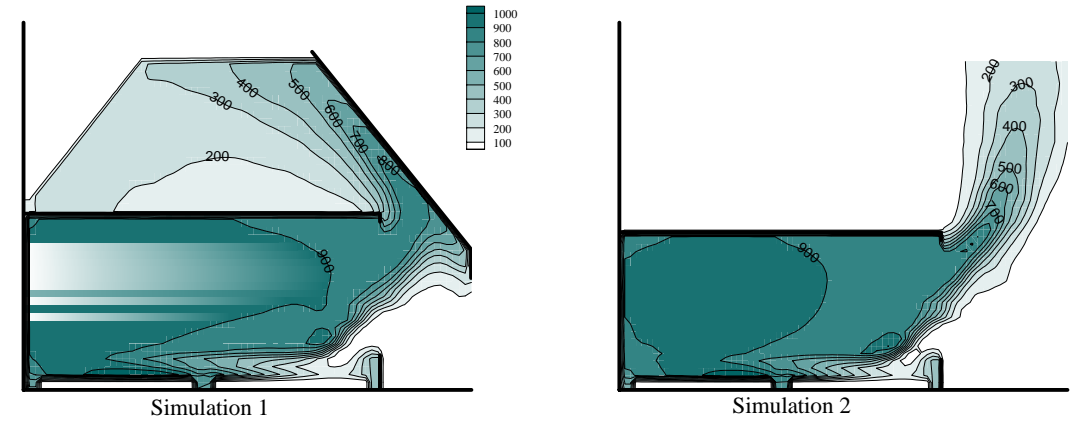

Fig. 10. Effect of hood on average temperature field $\left({ }^{\circ} \mathrm{C}\right)$. Side view.

It can be noted that external flames are obviously strongly deflected whereas the temperature field inside the compartment is only slightly disturbed by the presence of the hood. However, local internal temperatures are a little higher in simulation 1.

In Fig. 11, the average temperature differences between the two simulations are reported in a horizontal plane located $1.20 \mathrm{~m}$ above the floor. The variation is positive when 
simulation 1 leads to higher temperature than simulation 2. On the whole, significant values of temperatures inside the room are not strongly disturbed by the effect of the hood. For the major part of the room, differences are less than $50^{\circ} \mathrm{C}$. Nevertheless, close to the room center, differences as high as one hundred degrees are observed between the two cases. So, the effect of the hood above the compartment is to slightly increase internal temperatures in the compartment. The dissymmetry induced by the position of the opening is also highlighted by Fig. 11.
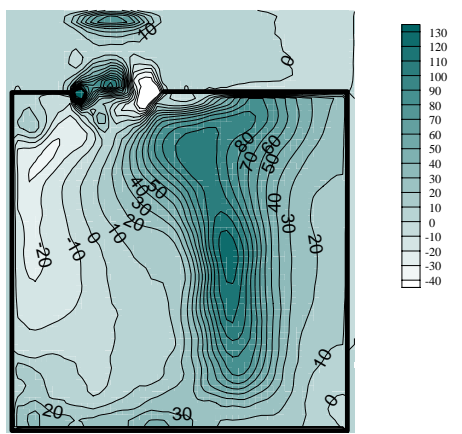

Fig. 11. Temperature variation between simulation 1 and simulation $2\left({ }^{\circ} \mathrm{C}\right)$.

Plan view located at $1.2 \mathrm{~m}$ above the ground.

Figure 12 shows a comparison for the heat release rate per unit volume (using the same average as above). A stronger heat release rate is found outside the compartment in simulation 2.
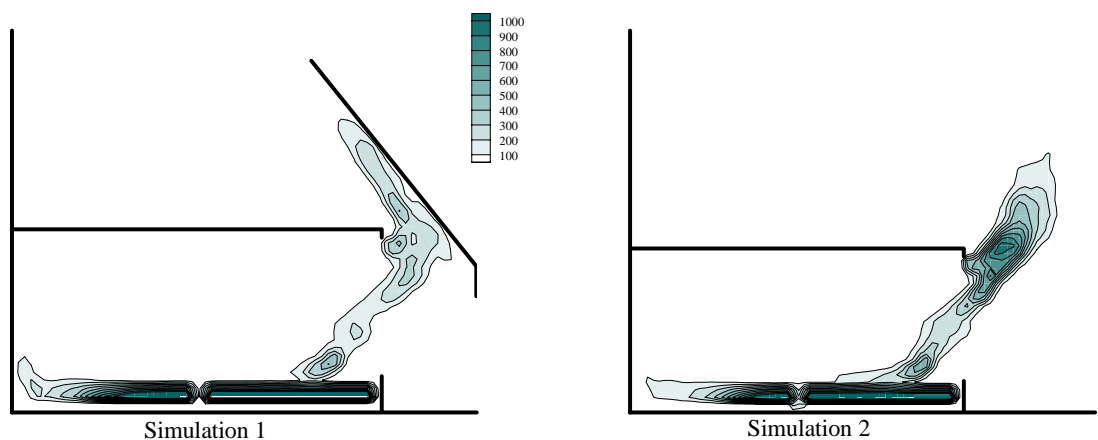

Fig. 12. Effect of hood on average heat release rate per unit of volume $\left(\mathrm{kW} / \mathrm{m}^{3}\right)$. Side view.

The global heat release rates inside the compartment for the two simulations are reported in Fig. 13. This value, during fully developed fire stage, is clearly different between the two simulations. It corresponds to the heat release rate within the compartment, not including burning in the door plume. The total heat release rate computed by FDS follows the input data and is not presented in Fig. 13. The presence of the hood disturbs the flows emerging from the opening and entering in the compartment, so that lesser heat is released outside. 


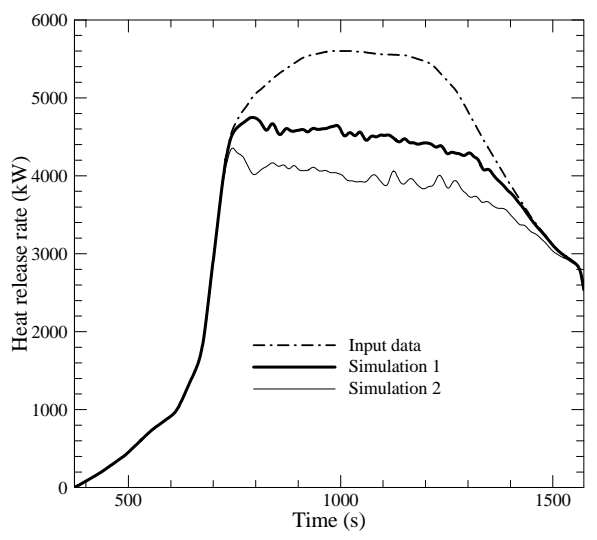

Fig. 13. Smoothed heat release rates inside the compartment for simulations 1 and 2.

It has been explained above that the measured CO yield $0.076 \mathrm{~kg} / \mathrm{kg}$ of fuel is relatively high compared to usually measured values. It is generally accepted that measurements of CO concentration are underestimated [10] due to chemical reactions with fresh air in the hood. But the present calculation shows that the hood has not the same effect: it limits the combustion in the external flaming by restricting the mixing, leading to a higher $\mathrm{CO}$ yield. This effect can not be shown by the simulation without the hood because of lack of combustion chemistry modeling. Indeed, the CO yield is proportional to the HRR, and is then only transported.

\section{CONCLUSION}

This work presents a use of CFD to estimate the relevance of a fire test results by simulating the test with and without its experimental device. In the present paper, the effect of a calorimeter hood has been investigated.

This methodology requires two numerical simulations. The first one is used as a calibration of some numerical parameters. Once the numerical tool is able to correctly reproduce the experimental values, it can be used to study physical processes involved in the test but not recorded. The reliability of the experimental results can thus be estimated using numerical tool capabilities. In a second phase, it is possible to perform another simulation in which the experimental device has been removed. Then, a comparison between the two simulations can help assessing the impact of the device in the real test. An interesting point concerning these numerical simulations is the ability to compare physical values which are not available in every location from the test. That makes overall assessment easier.

The application of the approach developed in this paper to natural fire of a hotel bedroom under a hood has led to some recommendations. In one hand, it has been shown that measurement of the heat release seems to be correctly performed using the calorimeter hood, even if this latter was located quite close to the compartment. No combustion gases have been lost without flowing through the venturi duct. On the other hand, the effect of the calorimeter hood in this work can be neglected if a global view of fire into the compartment is sufficient. It has been shown that typical temperature field is not strongly disturbed by the presence of the hood. 
Nevertheless, if a focus on local temperature values is required, the effect of the calorimeter hood can have some importance. Indeed, temperature field in the room can present local variation between the two simulations, which can lead to a different fire evolution. This point has not been well investigated in this study because the same heat release rate was used for the two numerical calculations. In other words, it is not certain that the real heat release rate curve would have been the same without the hood.

\section{ACKNOWLEDGEMENTS}

The experimental investigation was financed by the Ministry of Interior (Direction de la Défense et de la Sécurité Civiles) of France.

\section{REFERENCES}

[1] Janssens, M.L., Parker, W.J., “Oxygen Consumption Calorimetry,” Heat release in fire, Elsevier Applied Science. (ed.), 1992, p. 31/59.

[2] Huggett, C. "Estimation of the Rate of Heat Release by Means of Oxygen Consumption Measurements," Fire and Materials, 12, (1980).

[3] Drysdale, D., An Introduction to Fire Dynamics, John Wiley and Sons, Chichester, 1985.

[4] Curtat, M., Physique du Feu pour l'Ingénieur, Traîté de Physique du Bâtiment, Tome 3, Editions CSTB.

[5] Cooper, L. Y. "Some Factors Affecting the Design of a Furniture Calorimeter Hood,” NISTIR 5298, National Institute of Standards and Technology, 1993.

[6] Joyeux, D., "Etude Expérimentale Caractérisant un Incendie Dans un Hôtel," INC 98/24, DJ/IM, CTICM, 1998.

[7] Joyeux, D., “Etude de faisabilité d'application de l'ingénierie au feu à un hôtel," INC 96/355, DJ/IM, CTICM, 1996.

[8] Leborgne, H. "Etude expérimentale d'un feu caractérisant un incendie survenant dans une chambre d'hôtel,” Test report 96-S-511, CTICM, 1997.

[9] McGrattan, K., "Fire Dynamics Simulator (version 4) - Technical Reference Guide,” NIST Special Publication 1018, National Institute of Standards and Technology, Gaitherburg, Maryland, 2004.

[10] Wieczorek, C., Vandsburger, U., and Floyd, J., "An Evaluation of the Global Equivalence Ratio Concept for Compartment Fires: Data Analysis Methods,” Fire Protection Engineering, 14, pp. 9-31, (2004). 
